\title{
Radar Remote Sensing Estimates of Waves and Wave Forcing at a Tidal Inlet
}

\author{
Guillermo M. Díaz Méndez and Merrick C. Haller \\ School of Civil and Construction Engineering, Oregon State University, Corvallis, Oregon \\ BRITT RAUBENHEIMER AND STEVE ElgaR \\ Woods Hole Oceanographic Institution, Woods Hole, Massachusetts \\ DAVID A. HONEGGER \\ School of Civil and Construction Engineering, Oregon State University, Corvallis, Oregon
}

(Manuscript received and in final form 25 November 2014)

\begin{abstract}
The time and space variability of wave transformation through a tidal inlet is investigated with radar remote sensing. The frequency of wave breaking and the net wave breaking dissipation at high spatial resolution is estimated using image sequences acquired with a land-based X-band marine radar. Using the radar intensity data, transformed to normalized radar cross section $\sigma^{0}$, the temporal and spatial distributions of wave breaking are identified using a threshold developed via the data probability density function. In addition, the inlet bathymetry is determined via depth inversion of the radar-derived frequencies and wavenumbers of the surface waves using a preexisting algorithm (cBathy). Wave height transformation is calculated through the $1 \mathrm{D}$ cross-shore energy flux equation incorporating the radar-estimated breaking distribution and bathymetry. The accuracy of the methodology is tested by comparison with in situ wave height observations over a 9-day period, obtaining correlation values $R=0.68$ to 0.96 , and root-mean-square errors from 0.05 to $0.19 \mathrm{~m}$. Predicted wave forcing, computed as the along-inlet gradient of the cross-shore radiation stress $\partial S_{x x} / \partial x$ was onshore during high-wave conditions, in good agreement $(R=0.95)$ with observations.
\end{abstract}

\section{Introduction}

Remote sensing technology offers some advantages for the continuous monitoring of nearshore environments because the sensors are removed from frequently harsh in situ conditions and often provide easier access to real-time data (Holman and Haller 2013) than provided by self-recording sensors. In addition, the larger footprints of remote sensors can be a significant benefit in areas where spatial variability is high. However, remote sensing observations often are a more indirect form of measurement of fundamental hydrodynamic parameters than obtained with most in situ sensors.

Primary drivers of the hydrodynamics in the nearshore are spatial gradients in the radiation stresses, which are

Corresponding author address: Guillermo M. Díaz Méndez, School of Civil and Construction Engineering, Oregon State University, 101 Kearney Hall, Corvallis, OR 97331.

E-mail: guillermo.diaz@oregonstate.edu functions of wave height and direction (Longuet-Higgins and Stewart 1964). The spatial wave transformation and hence, the radiation-stress gradients, are affected by refraction and shoaling, and are modulated by dissipation in and around the surfzone (Svendsen 2006). Recent in situ observations of waves and currents at the tidal inlet investigated here (Wargula et al. 2014) demonstrated that the breaking-induced gradient of the cross-shore radiation stress contributed significantly to the subtidal alongchannel momentum balance, enhancing the flood flows into the inlet, particularly during storms, similar to results at other inlets (Malhadas et al. 2009; Bertin et al. 2009; Dodet et al. 2013; Orescanin et al. 2014).

Remote sensing observations (optical) of wave dissipation have been used successfully to assess the crossshore evolution of the momentum balance in laboratory surfzones (Haller and Catalán 2009; Flores et al. 2013), and remote observations (infrared) of wave breaking have been used to assess the depth-induced dissipation over a longshore sandbar on an open beach (Carini et al. 


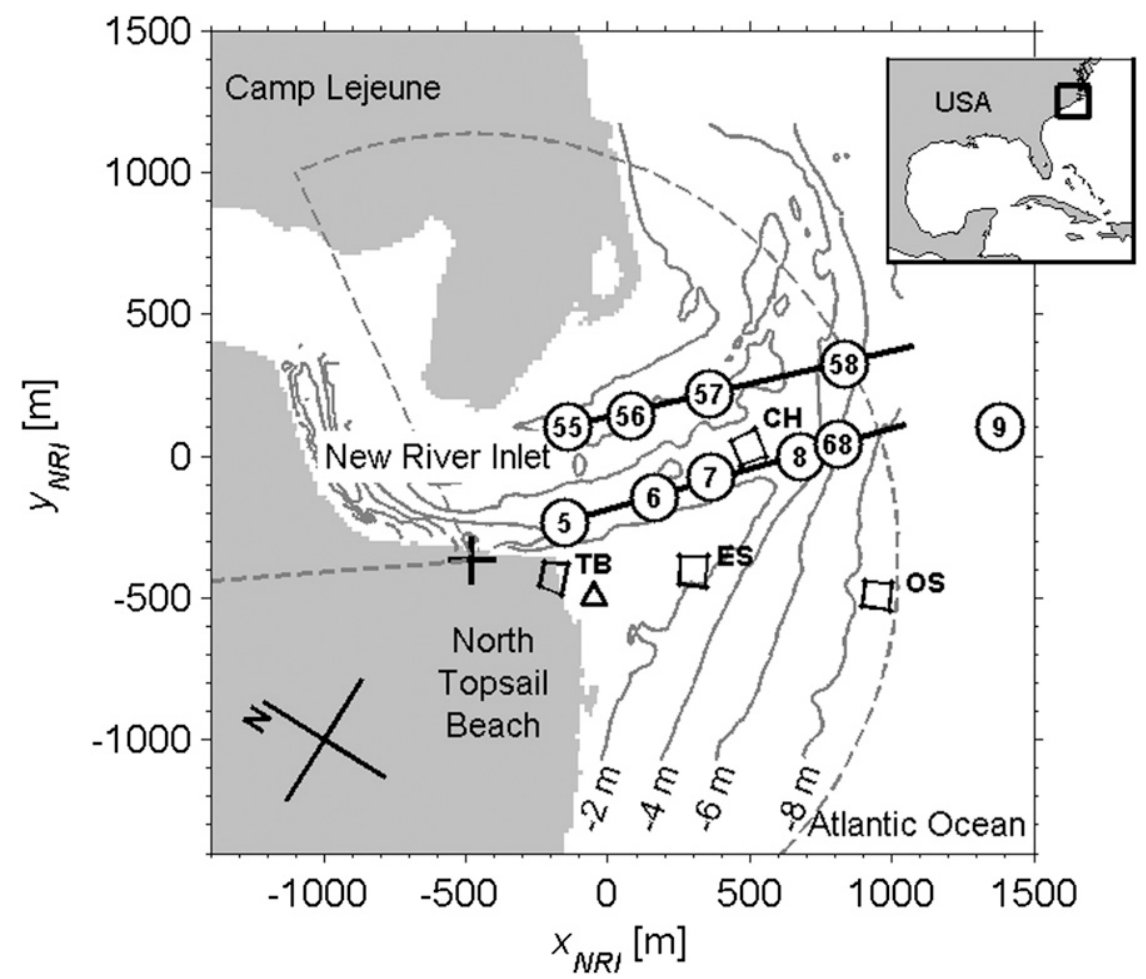

FIG. 1. Experiment site (the location of New River Inlet, North Carolina, along the U.S. Atlantic coast is shown in the inset map). Gray-shaded areas are land, and gray curves are depth contours $(-2,-4,-6$, and $-8 \mathrm{~m}$ NAVD88). The plus sign near $(-477,-365 \mathrm{~m})$ denotes the location of the radar, and the dashed curve indicates the limit of the $1.5 \mathrm{~km}$ radius radar footprint. The triangle indicates the location of the meteorological station, circles are collocated buried pressure gauges (sampled at $2 \mathrm{~Hz}$ ) and ADVs (sensors 55-68, sampled at $2 \mathrm{~Hz}$ ), profilers (sensors 5-8, 1-min average samples), and a combination velocimeter (sensor 9, 2-Hz samples, $1024 \mathrm{~s}$ every half hour) and profiler (1-min average samples for 12 min every half hour). Trapezoids are the areas for which the PDF analysis was performed. Thick black lines are the cross-shore transects.

2015, manuscript submitted to J. Geophys. Res. Oceans). Doppler radar ( $\mathrm{S}$ band) estimates of wave orbital velocities have also been used to characterize both the nearshore wave transformation and bathymetry along a single crossshore transect (McGregor et al. 1998).

Here, an approach based almost entirely on remote sensing observations is presented to evaluate the time and space variability of wave transformation. The observations were obtained near an energetic tidal inlet with substantial spatial variability and wave conditions that are modulated strongly by the tide. The remote sensing and in situ observations are described in section 2 , and the methodology for identifying wave breaking, estimating wave breaking dissipation, and calculating wave height transformation are presented in section 3. Results are discussed, including comparisons of remote sensing with in situ observations in section 4 , followed by a brief discussion of accuracy and sources of error. In addition, the remotely sensed wave height transformation results are used to estimate radiation-stress forcing, and compared with estimates from in situ measurements. Conclusions are given in section 5 .

\section{Field observations}

Observations were obtained 7-16 May 2012 at New River Inlet (NRI), a small (1 km wide at the mouth), tide-dominated estuary located on the North Carolina Atlantic coast (Fig. 1). Abundant shoals and a complex sandbar system characterize the inlet mouth and flanking beaches. Tidal currents were as high as $1.5 \mathrm{~m} \mathrm{~s}^{-1}$ and were in phase with the $\pm 1-\mathrm{m}$ tidal amplitude. Offshore (9-m water depth) significant wave heights $\left[H_{s}, 4\right.$ times the standard deviation of sea surface elevation fluctuations in the frequency $(f)$ band from 0.05 to $0.30 \mathrm{~Hz}$ ] ranged from 0.5 to $1.5 \mathrm{~m}$, centroidal (energy weighted) frequencies $f_{c}$ ranged from 0.11 to $0.18 \mathrm{~Hz}$, and waves approached the region from the east-southeast to southeast (Wargula et al. 2014). 


\section{a. Radar collections}

An X-band wave imaging marine radar, consisting of a commercial SI-TEX Koden radar and an acquisition system developed by Imaging Science Research, Inc. was deployed on the southwest shore of the inlet $\left(x_{\mathrm{NRI}}=\right.$ $-477.3 \mathrm{~m}$ and $y_{\mathrm{NRI}}=-365.2 \mathrm{~m}$ in Fig. 1). Mounted atop of a scaffolding structure, every half hour the radar recorded 1024 images of the ocean surface over a footprint radius of 1.5 (from 7 to 9 May) or $3.0 \mathrm{~km}$ (from 9 to 16 May) with an angular coverage of about $300^{\circ}$ (Fig. 1). The 9-ft-long HH-polarized antenna rotated at approximately $46.7 \mathrm{rpm}$, thus taking about $22 \mathrm{~min}$ to acquire the 1024 images.

\section{b. In situ data}

Waves and currents were measured along two transects across the ebb shoal and offshore (9-m water depth) (Fig. 1). Wave heights on the ebb shoal were estimated by correcting bottom pressure to sea surface elevation using linear theory. Offshore wave heights were measured with an acoustic surface-tracking beam. Wind speed and direction, in addition to standard meteorological parameters, were recorded $100 \mathrm{~m}$ offshore of North Topsail Beach (Fig. 1). In situ GPS-based bathymetric surveys (Fig. 1) were conducted on 16 April, and 2, 10, 17, and 25 May.

\section{Methodology}

\section{a. Breaker identification and estimation of the fraction of breaking waves $Q_{b}$}

To identify the radar signal associated with breaking waves, histograms [which represent the probability density function (PDF); Catalán et al. 2011] of normalized radar cross section $\sigma^{0}$ were analyzed. Recorded radar intensity, stored as a function of range, azimuth, and time, was calibrated during postprocessing to compensate for the intensity falloff with range (Gommenginger et al. 2000 ) and to compare $\sigma^{0}$ values with previous studies. Calibration coefficients were estimated during a later campaign conducted at the mouth of the Columbia River in 2013, and are considered approximate. The PDFs were computed from the calibrated data extracted from four distinct regions of the radar footprint (black trapezoids in Fig. 1) where environmental conditions were expected to differ: North Topsail Beach (TB, where waves were observed to break at all times), the south ebb shoal (ES, where waves broke during low tide), the main inlet channel $(\mathrm{CH}$, where waves may break as a consequence of wave-current interaction), and offshore (OS, where waves were not expected to break).

Previous studies (Trizna et al. 1991; Farquharson et al. 2005; Catalán et al. 2011) have shown that the occurrence of a secondary peak in the radar PDFs [i.e., an inflection point in its otherwise smooth exponential decay toward high normalized radar cross section (NRCS) values] is related to a change in the microwave scattering mechanism, and indicative of breaking events. There also is evidence that X-band scattering levels $\left(\sigma^{0}\right)$ from active breaking are constant in the surfzone (Haller and Lyzenga 2003; Catalán et al. 2014). Thus, the NRCS values associated with the secondary peaks were used to determine a threshold to discriminate active breaking from nonbreaking waves and remnant foam that could be applied to all the radar runs. With this breaking threshold, $\sigma_{\mathrm{br}}^{0}$, radar snapshots were masked, enabling the production of maps of breaking wave events. The total number of broken waves per radar collection $N_{b}$ was calculated through the gradient of the binary (i.e., above or below the threshold) time series by counting the number of positive slopes for each individual radar resolution cell. Given $N_{b}$, the fraction of breaking waves $Q_{b}$ at a given range and azimuth $(r, \theta)$ was estimated as

$$
Q_{b}(r, \theta)=\frac{N_{b}(r, \theta)}{N_{\text {tot }}}
$$

with $N_{\text {tot }}=\tau f_{p}$, where $\tau$ is the duration of the wave record (i.e., the length of each radar collection, $1320 \mathrm{~s}$ approximately). The peak frequency $f_{p}$ and the wavenumber vector $\mathbf{k}$ were estimated from the radar-derived wavenumberfrequency spectrum $S(\mathbf{k}, f)$, computed via the 3D FFT (Young et al. 1985) at a location offshore of the ebb shoal in 9-m depth (coincident with region OS, see Fig. 1). Unrealistic $f_{p}$ values from radar collections with poor signalto-noise ratios (SNR), commonly associated with low sea surface roughness, were removed from the analyses.

\section{b. Cross-shore wave height transformation and wave forcing}

The 2D wave-action balance equation describes the evolution of wave propagation in space $\mathbf{x}$ and time $t$ as (Kirby 1984)

$$
\frac{\partial}{\partial t}\left(\frac{E}{\sigma}\right)+\frac{\partial}{\partial \mathbf{x}}\left[\left(\mathbf{U}+\mathbf{c}_{g}\right) \frac{E}{\sigma}\right]=\frac{D_{w}}{\sigma},
$$

where $E / \sigma$ is the wave action, which is conserved in the presence of currents. The wave energy density is $E=$ $\rho g H^{2} / 8 ; \rho$ and $g$ are the seawater density and acceleration of gravity, respectively; $\sigma$ is the relative wave frequency; $\mathbf{c}_{g}$ is the group velocity vector; and $D_{w}$ is the wave energy dissipation owing to breaking. Measurements collected via surface drifters during this field program (Zippel and Thomson 2015) demonstrate the onshore/offshore modulation of wave breaking at New River Inlet. Model-data comparisons (Chen et al. 2014, 

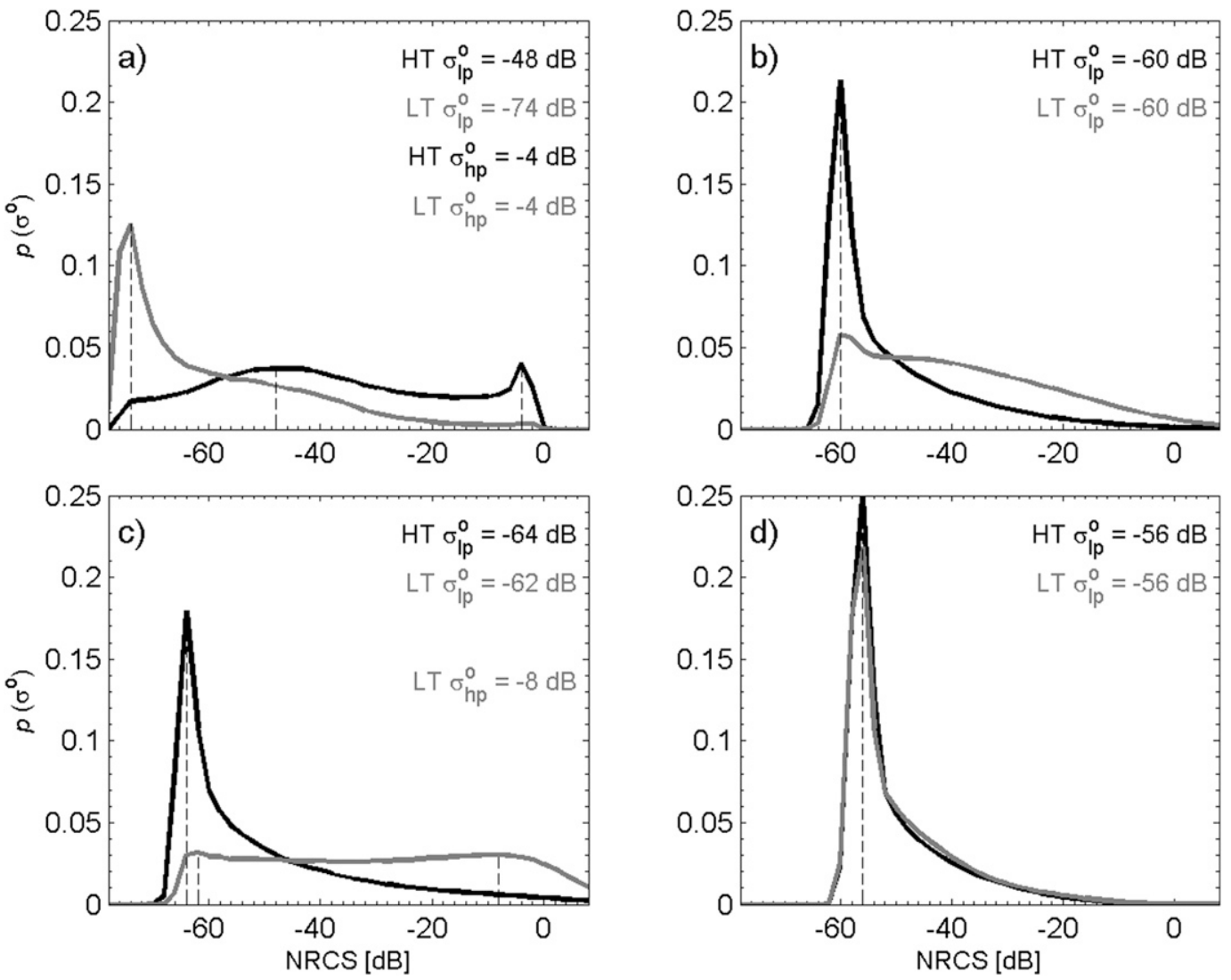

FIG. 2. Probability density vs normalized radar cross section for (a) North Topsail Beach, (b) main inlet channel, (c) south ebb shoal, and (d) offshore for high-tide (black curves) and low-tide (gray curves) conditions. High and low NRCS peaks are indicated as $\sigma_{\mathrm{hp}}^{0}$ and $\sigma_{\mathrm{lp}}^{0}$, respectively.

manuscript submitted to J. Geophys. Res. Oceans) suggest that the modulation of wave heights in the inlet was caused mainly by tide-dependent depth changes, rather than the direct effect of wave-current interaction. Hence, neglecting the presence of currents $\mathbf{U}$, and assuming stationarity, Eq. (2) becomes

$$
\frac{\partial}{\partial \mathbf{x}}\left(\frac{E \mathbf{c}_{g}}{\sigma}\right)=\frac{D_{w}}{\sigma} .
$$

Considering the evolution of wave action along a 1D cross-shore transect $\mathbf{x}$, in which $c_{g x}=c_{g} \cos \alpha$ is the $\mathbf{x}$ component of the group velocity vector, and $\alpha$ is the wave propagation direction with respect to the crossshore coordinate, Eq. (3) may be solved numerically through a forward differencing scheme in space as

$$
\left(E c_{g x}\right)_{i+1}=\left(E c_{g x}\right)_{i}-D_{w} \Delta x .
$$

Equation (4) assumes that depth contours are straight and parallel along the 1D numerical domain, which is violated in this inlet. Wave refraction is computed via Snell's law.
The fraction of breaking waves $Q_{b}$ was used to calculate the dissipation $D_{w}$ in Eq. (4) to predict the crossshore wave height transformation. This method is similar to studies (Haller and Catalán 2009; Flores et al. 2013) that calculated dissipation through the measurement of roller lengths. From the maps of radar-derived $Q_{b}$, the dissipation was calculated using a parametric model given by (Janssen and Battjes 2007)

$$
D_{w}=\frac{3 \sqrt{\pi}}{16} B \rho g \frac{H_{\mathrm{rms}}^{3}}{h} f_{p} Q_{b},
$$

where $B$ is a tunable parameter that controls the intensity of the wave dissipation, $H_{\mathrm{rms}}$ is the root-meansquare wave height $\left(H_{\mathrm{rms}}=H_{s} / \sqrt{2}\right)$, and $h$ is the local water depth. Equation (4) was solved along two 1250-mlong transects, discretized using $\Delta x=5 \mathrm{~m}$, located through the mouth of NRI and the ebb shoal. The length and orientation of the transects were chosen to coincide approximately with the location of stations 5-68 along the main (south) inlet channel, and stations 55-58 along the secondary (north) channel, extending across the tidal shoals, but not beyond the location of station 9 in 

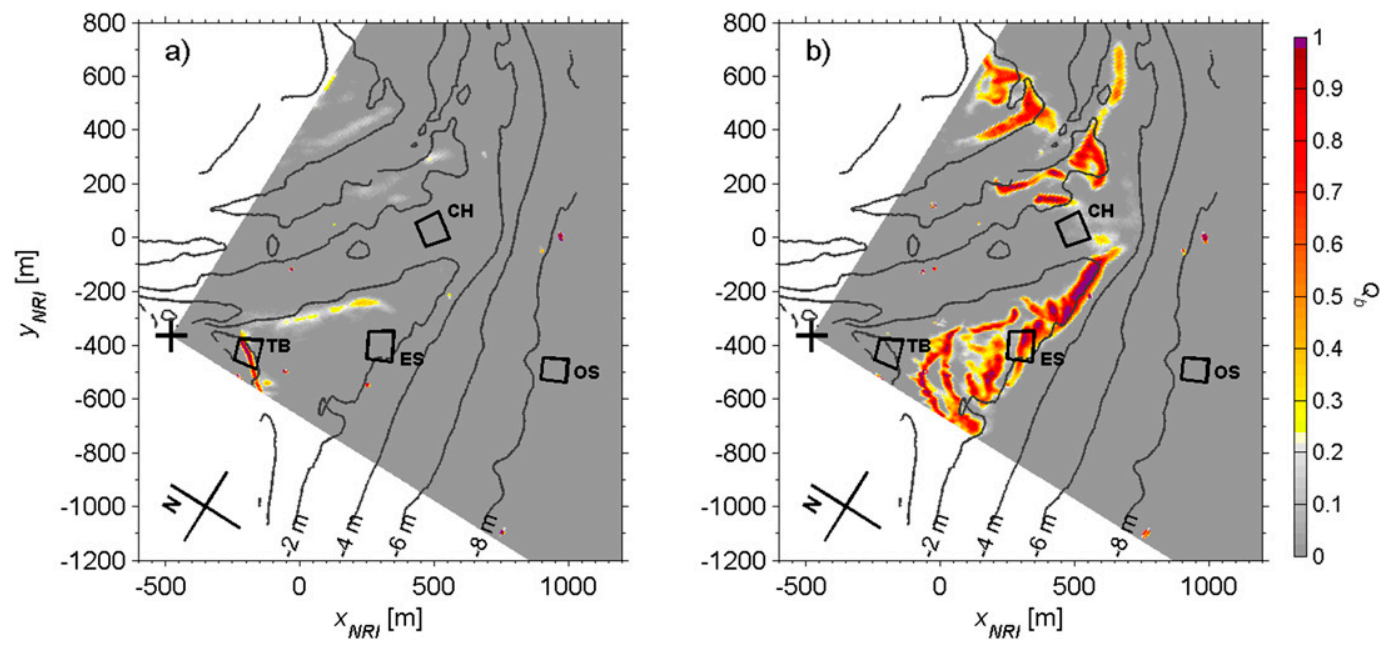

FIG. 3. Maps (color scale on the right) of the fraction of breaking $Q_{b}$ as a function of spatial coordinate corresponding to (a) high (0230 UTC 10 May) and (b) low (0900 UTC 10 May) tide. Gray curves are depth contours (see Fig. 1). The maps have been cropped to display data in the east-south (i.e., azimuth $90^{\circ}-180^{\circ}$ from true north) sector of the radar footprint only. The plus sign is the location of the radar.

9-m depth (Fig. 1). The wave direction was estimated from the radar data as the direction associated with the peak of the spectrum computed from the 3D FFT spectral estimates (section 3a). The tidal elevation and the significant wave height measured in situ at station 9 were the only nonradar-derived parameters used as model inputs. Wave forcing, given here by the gradient of the cross-shore radiation stress $S_{x x}$,
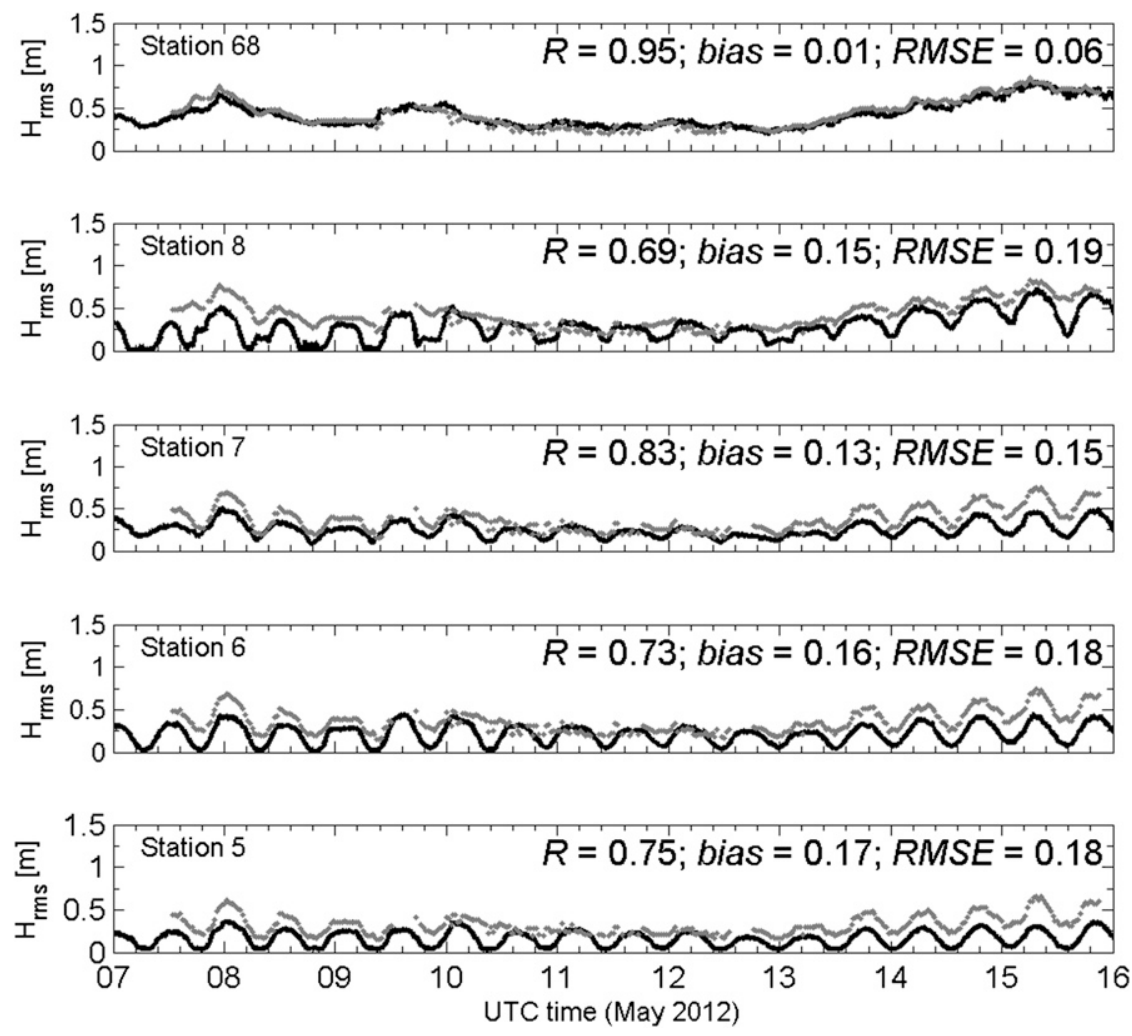

FIG. 4. Predicted (gray) and observed (black) $H_{\mathrm{rms}}$ vs time for locations along the south inlet transect (sensors 5-8 and 68, Fig. 1). 

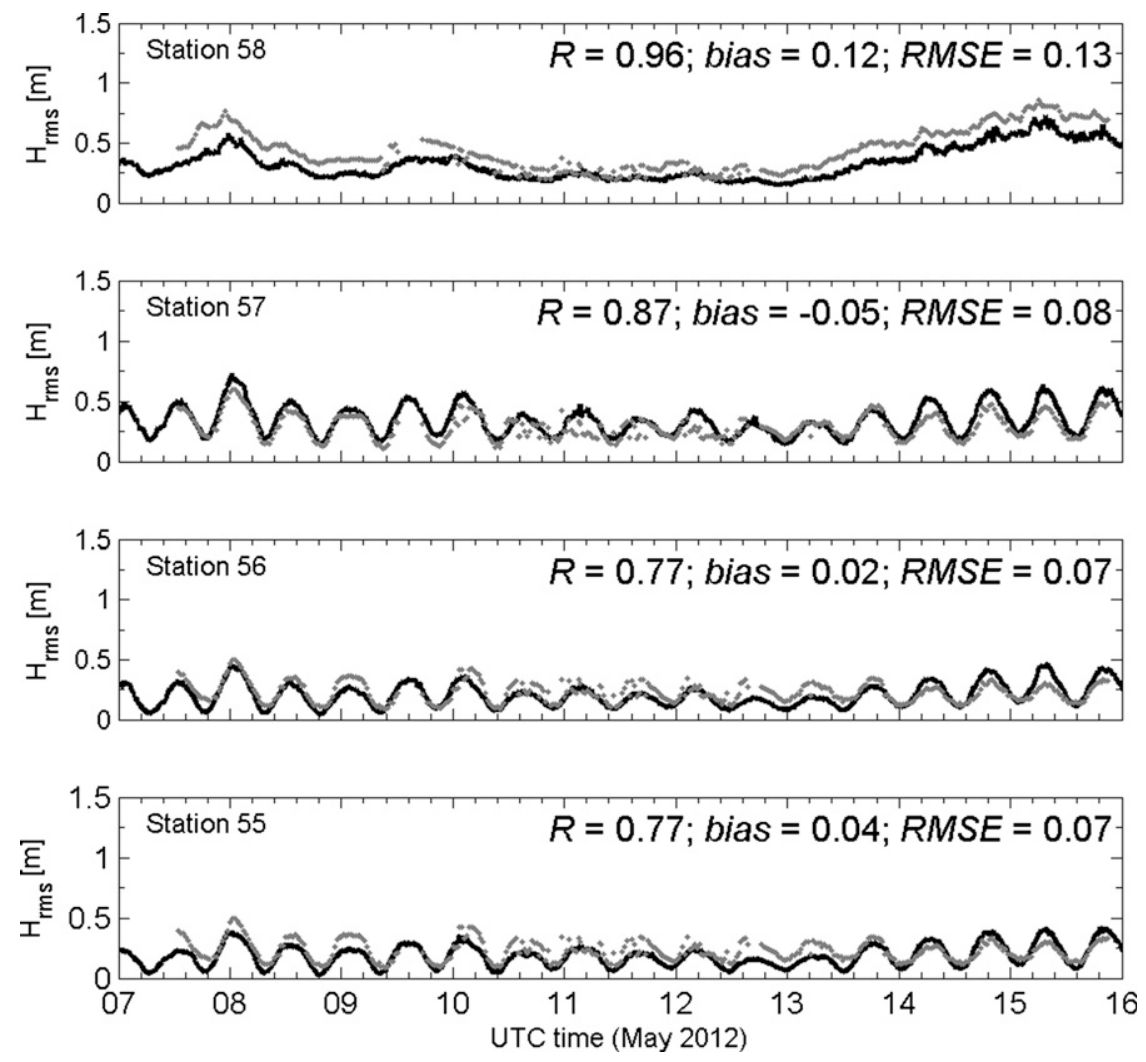

FIG. 5. Predicted (gray) and observed (black) $H_{\text {rms }}$ vs time for locations along the north inlet transect (sensors 55-58, Fig. 1).

$$
\frac{\partial S_{x x}}{\partial x}=\frac{\partial}{\partial x}\left\{E\left[\left(\cos ^{2} \alpha+1\right) \frac{c_{g}}{c}-\frac{1}{2}\right]\right\}
$$

was computed by solving Eq. (4) on the numerical domain. Likewise, the derivatives in Eq. (6) were calculated on the same grid (i.e., $\Delta x=5 \mathrm{~m}$ ).

\section{c. Bathymetry}

The bathymetric grid used for wave transformation was interpolated from bathymetry computed from radar data collected between 7 and 16 May using the cBathy algorithm with a 25-m horizontal resolution (Holman et al. 2013). The algorithm estimates spatially varying

TABLE 1. Willmott skill scores from prior model results (Chen et al. 2014, hereafter Ch14, manuscript submitted to J. Geophys. Res. Oceans), and skill scores, correlation coefficients $R$, and error metrics (bias and RMSE) for the 1D wave transformation model results computed using $A$ : surveyed bathymetry and parametric dissipation (Janssen and Battjes 2007), B: surveyed bathymetry and radarderived dissipation, and $C$ : radar-derived bathymetry and dissipation.

\begin{tabular}{|c|c|c|c|c|c|c|c|c|c|c|c|c|c|}
\hline \multirow[b]{2}{*}{ Stations } & \multicolumn{4}{|c|}{$H_{\mathrm{rms}}$ model skill $\chi$} & \multicolumn{3}{|c|}{$R[-]$} & \multicolumn{3}{|c|}{$\operatorname{Bias}(\mathrm{m})$} & \multicolumn{3}{|c|}{ RMSE (m) } \\
\hline & Ch14 & $A$ & $B$ & C & $A$ & $B$ & $C$ & $A$ & $B$ & $C$ & $A$ & $B$ & $C$ \\
\hline \multicolumn{14}{|l|}{ South transect } \\
\hline 68 & 0.59 & 0.97 & 0.97 & 0.97 & 0.96 & 0.96 & 0.95 & 0.01 & 0.01 & 0.01 & 0.05 & 0.05 & 0.06 \\
\hline 8 & N/A & 0.66 & 0.71 & 0.71 & 0.63 & 0.70 & 0.69 & 0.18 & 0.15 & 0.15 & 0.23 & 0.20 & 0.19 \\
\hline 7 & N/A & 0.56 & 0.70 & 0.68 & 0.75 & 0.85 & 0.83 & 0.18 & 0.12 & 0.13 & 0.20 & 0.15 & 0.15 \\
\hline 6 & 0.75 & 0.54 & 0.68 & 0.63 & 0.60 & 0.79 & 0.73 & 0.20 & 0.14 & 0.16 & 0.23 & 0.16 & 0.18 \\
\hline 5 & 0.87 & 0.46 & 0.59 & 0.57 & 0.60 & 0.78 & 0.75 & 0.23 & 0.16 & 0.17 & 0.25 & 0.18 & 0.17 \\
\hline \multicolumn{14}{|l|}{ North transect } \\
\hline 58 & 0.70 & 0.85 & 0.85 & 0.85 & 0.97 & 0.97 & 0.96 & 0.12 & 0.12 & 0.12 & 0.13 & 0.13 & 0.13 \\
\hline 57 & 0.76 & 0.95 & 0.86 & 0.88 & 0.91 & 0.83 & 0.87 & 0.00 & -0.06 & -0.05 & 0.05 & 0.09 & 0.08 \\
\hline 56 & 0.82 & 0.85 & 0.79 & 0.83 & 0.92 & 0.64 & 0.77 & 0.07 & -0.02 & 0.02 & 0.08 & 0.08 & 0.07 \\
\hline 55 & 0.87 & 0.82 & 0.80 & 0.80 & 0.91 & 0.66 & 0.77 & 0.08 & -0.01 & 0.04 & 0.09 & 0.08 & 0.07 \\
\hline
\end{tabular}



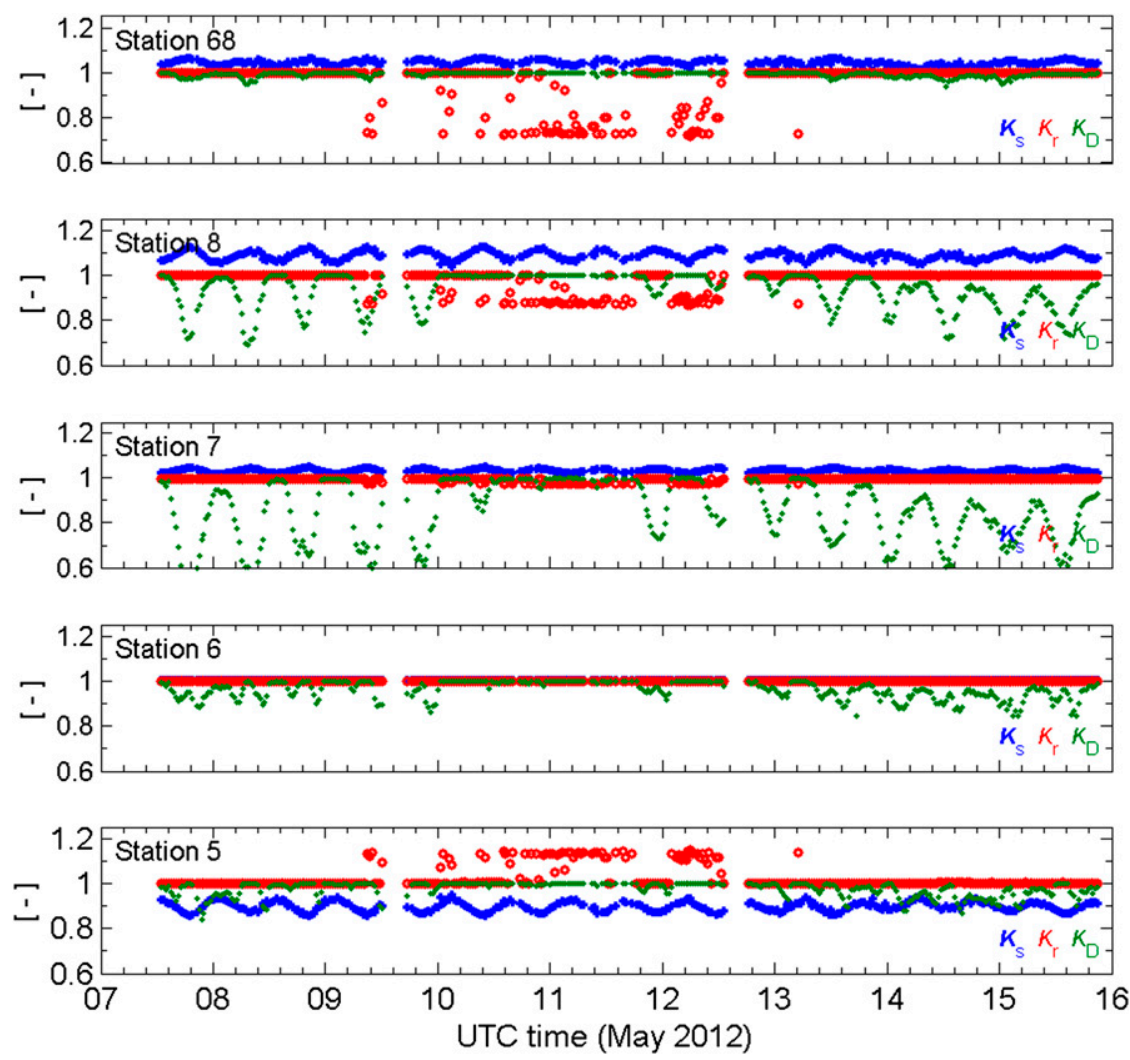

FIG. 6. Predicted shoaling $K_{s}$ (blue), refraction $K_{r}$ (red), and dissipation $K_{D}$ (green) coefficients vs time for locations along the south inlet transect (sensors 5-8 and 68, Fig. 1).

frequency $(f)$-wavenumber $(k)$ pairs and inverts the linear wave dispersion relation $\left[\sigma^{2}=g k \tanh (k h)\right]$ to obtain maps of bathymetry, $h(x, y)$, for every radar collection. To produce a smoother estimate of bathymetry, the tidal signal was removed from the $h$ time series using the data from the tide gauge at Wrightsville Beach, North Carolina (NOAA gauge station 8658163) and the resulting time series was averaged. For the wave transformation analysis, the tidal signal was reincorporated, producing time-varying depth profiles referenced to the North American Vertical Datum of 1988 (NAVD88). Differences between wave transformation results based on the cBathy-estimated bathymetry and those based on surveyed bathymetries were small (discussed in section 4).

\section{Results and discussion}

The shapes of the PDFs of $\sigma^{0}$ varied spatially (Fig. 2 compares the four panels with each other) and temporally, with a strong dependence on environmental conditions, particularly the tide. The distributions (Fig. 2) represent the mean PDFs (averages per NRCS bin) of all radar collections recorded within a 3 -h period centered on the minimum (gray curves) and maximum (black curves) tide levels between 7 and 16 May, at each of the four locations (TB, CH, ES, and OS; Fig. 1) described in section 3a. Consistent with previous studies, the PDFs corresponding to nonbreaking wave conditions showed a single, well-defined peak at low NRCS, followed by a relatively smooth exponential decay toward higher radar backscatter values. For example, the PDFs corresponding to $\mathrm{CH}$, ES, and OS (Fig. 1) are similar during high tide, with a single large peak in the -56 - to $-64-\mathrm{dB}$ range and an exponential decay toward high NRCS (Figs. 2b-d). The relatively lower NRCS peak $(-74 \mathrm{~dB})$ corresponding to TB (Fig. 2a) is the result of a calibration procedure that is only approximate and is less accurate at very close range. In addition, portions of this analysis box were exposed (i.e., dry) during low tide, which also lead to lower returns. In contrast, in the presence of active breaking, the PDFs exhibit a secondary peak at high NRCS. For example, the high-tide PDF corresponding to TB (Fig. 2a) is bimodal, with a smooth plateau at $-48 \mathrm{~dB}$ and a sharp peak at $-4 \mathrm{~dB}$. The low-tide PDFs corresponding to TB and ES (Figs. 2a and 2c) also are bimodal, with high NRCS peaks at -4 and $-8 \mathrm{~dB}$, respectively. The time (low or high tide) and space distributions of the breaking returns are consistent with aerial photographs 

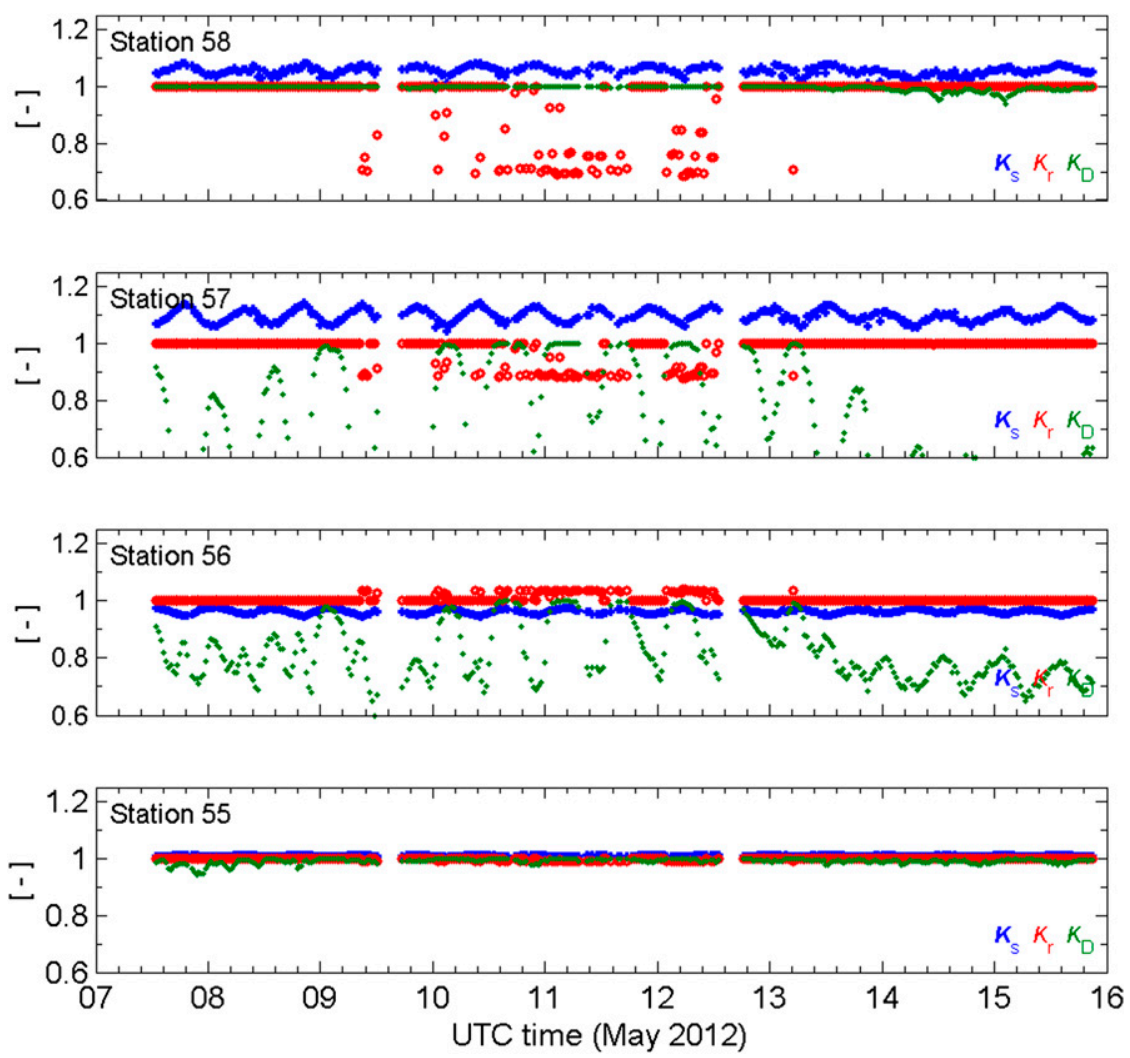

FIG. 7. Predicted shoaling $K_{s}$ (blue), refraction $K_{r}$ (red), and dissipation $K_{D}$ (green) coefficients vs time for locations along the North inlet transect (sensors 55-58, Fig. 1).

and land-based video imagery. During high tide, breaking waves were observed only at the shoreline, and during low tide breakers were observed on all the tidal shoals and submerged bars. The average low- and high-tide PDFs from OS showed no significant differences (Fig. 2d). The amplitude of the $\sigma^{0}=-4-\mathrm{dB}$ peak is correlated with the tide, with $R=0.86$ for region TB, and smaller negative correlations $R=-0.67$ and $R=-0.57$ for ES and $\mathrm{CH}$, respectively, consistent with the hypothesis that high NRCS values, associated with wave breaking, occur during high tide at TB and during low tide at $\mathrm{ES}$ and $\mathrm{CH}$. The correlation of the PDF amplitude at $\sigma^{0}=-4 \mathrm{~dB}$ with the tide at OS was not statistically significant. However, amplitude at $\sigma^{0}=-4 \mathrm{~dB}$ was correlated with the significant wave height (from station 9) in the OS $(R=0.75)$, $\mathrm{CH}(R=0.68)$, and ES $(R=0.68)$ regions, but not in TB $(R=-0.03)$. The wind speed $u_{10}$, measured near TB (Fig. 1), was not significantly correlated with the amplitude of $\sigma^{0}=-4 \mathrm{~dB}$ for any region.

Based on these results, the value of $-4 \mathrm{~dB}$ was selected as a threshold $\sigma_{\mathrm{br}}^{0}$ to distinguish active wave breaking. This threshold value was used to mask the radar data and create maps of the fraction of breaking waves $Q_{b}$ (Fig. 3). Strong breaking $\left(Q_{b}>0.7\right)$ occurred almost exclusively at North Topsail Beach during high tide (Fig. 3a, TB region). During low tide waves broke farther offshore (Fig. 3b, ES region), revealing the complex morphology of the tidal shoals and nearshore bar system. In addition, $Q_{b}$ estimates from the higher sea-state conditions observed on 1315 May exhibit strong breaking over the shoals (not shown), approximately coinciding with the $2-\mathrm{m}$ NAVD88 bathymetry contour during low tide. Breaking over the shoals persisted through the entire tidal cycle, with the higher $Q_{b}$ values displaced shoreward at high tide. These observations are in good agreement with results from a wave-averaged quasi3D circulation model [Nearshore Community Model System (NearCoM-TVD)] that showed that the location of the breaker zone over the NRI ebb tidal deltas is modulated by the tides and wave intensity (Chen et al. 2014, manuscript submitted to J. Geophys. Res. Oceans).

Time series of the predicted and observed cross-shore wave height transformation along the south (Fig. 4) and north (Fig. 5) transects illustrate that, except for the most seaward stations (68 and 58, located offshore of the ebb shoal in approximately 5-m depth), in situ wave heights 

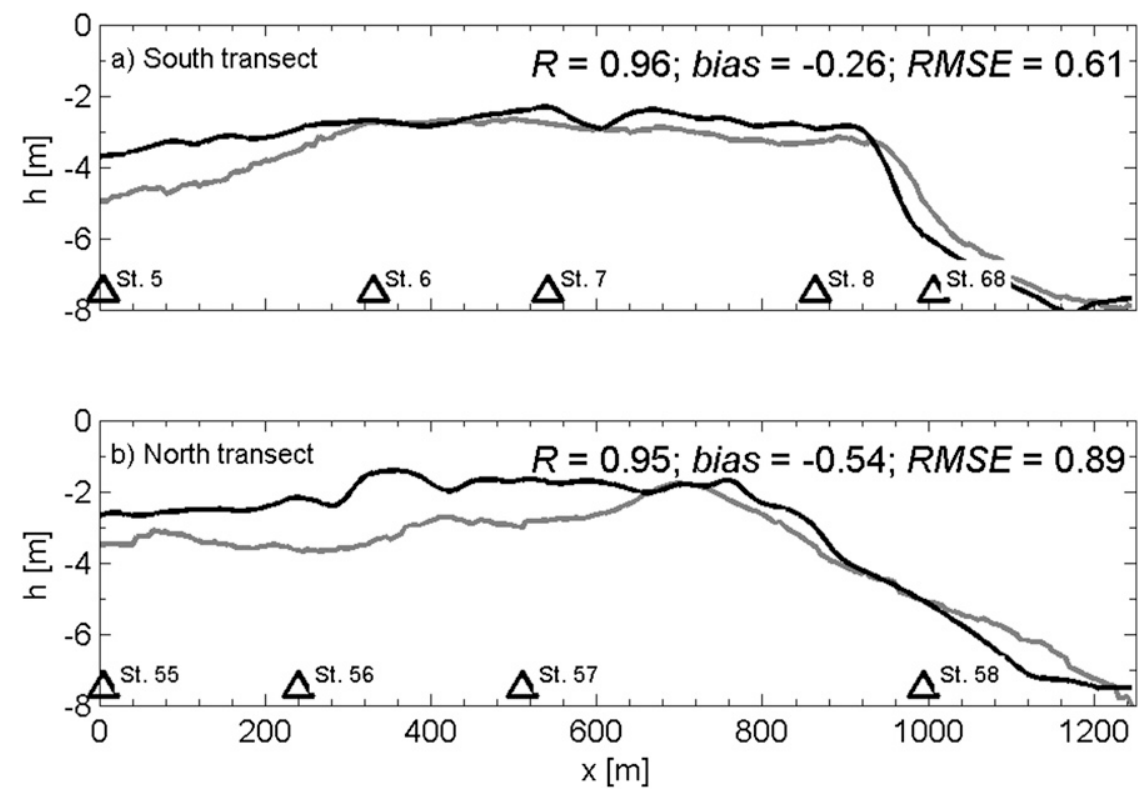

FIG. 8. Water depth vs cross-shore coordinate along the (a) south and (b) north transects estimated with radar and cBathy (gray curves) and with in situ bathymetric surveys (black curves). The radar-derived (surveyed) water depths at the along-transect locations of the in situ sensors (Fig. 1) (triangles) are $h_{5}=4.9(3.7) \mathrm{m}, h_{6}=2.7(2.7) \mathrm{m}, h_{7}=2.7(2.3) \mathrm{m}, h_{8}=3.3(2.9) \mathrm{m}$, $h_{55}=3.5(2.6) \mathrm{m}, h_{56}=3.6(2.2) \mathrm{m}, h_{57}=3.0(1.7) \mathrm{m}, h_{58}=5.1(5.1)$, and $h_{68}=5.3(6.1) \mathrm{m}$.

were depth limited, and thus were tidally modulated, resulting in bigger waves observed along the transects during high tide. Predicted wave heights along the south transect (Fig. 4) agree well with the in situ data $(R=0.69$ 0.95 and RMSE $=0.06-0.19 \mathrm{~m})$. A positive bias at all five stations, ranging between 0.01 and $0.17 \mathrm{~m}$, is indicative of a slight underestimation of the wave dissipation $D_{w}$ derived from the radar-derived $Q_{b}$ values. The $H_{\text {rms }}$ values along the north transect (Fig. 5) display a slightly higher level of agreement, with correlation values $R=0.77-0.96$, decreasing onshore. In comparison with results from the south transect, the lower bias and RMSE values in the north suggest a more accurate estimation of $D_{w}$. Willmott skill score values (Willmott 1981) range between 0.630.97 and $0.82-0.88$ for the south and north transects (Table 1), respectively, consistent with previous modeldata comparisons at this site (Chen et al. 2014, manuscript submitted to J. Geophys. Res. Oceans).

The relative importance of shoaling, refraction, and dissipation to wave height transformation between consecutive stations is investigated by recasting the calculated wave transformation in the form of linear shoaling, refraction, and dissipation coefficients. In this form, the wave height at each station depends on the height at the seaward station along the transect multiplied by the product of the coefficients, given by $H_{(i+1)}=$ $\left(K_{r} K_{s} K_{D}\right) H_{(i)}$. The local time-varying coefficients were calculated as

$$
\begin{aligned}
& K_{s}=\sqrt{\frac{\left(c_{g}\right)_{i}}{\left(c_{g}\right)_{i+1}}, \quad K_{r}}=\sqrt{\frac{(\cos \alpha)_{i}}{(\cos \alpha)_{i+1}}}, \quad \text { and } \\
& K_{D}=\sqrt{\frac{\left(H_{\mathrm{rms}}\right)_{i+1}}{\left(H_{\mathrm{rms}}\right)_{i} K_{s} K_{r}}},
\end{aligned}
$$

where $K_{s}$ and $K_{r}$ represent linear shoaling and refraction, respectively; $K_{D}$ is an analogous dissipation coefficient; and $i$ and $i+1$ are the indices of two adjacent stations. These coefficients vary in time at each station (Figs. 6 and 7). Shoaling (blue symbols in Figs. 6 and 7) is strongly modulated by the tide at all locations, oscillating between 1.0 and 1.2, except at stations 5 and 56, where the local water depth increases, inducing waves to deshoal $\left(K_{s}<1\right.$ and negatively correlated with the tide). The wave propagation directions were closely aligned with the orientation of the two transects, and thus the refraction coefficient (red symbols in Figs. 6 and 7) usually is about one. Large deviations from this value (e.g., near 10-13 May in Fig. 6 for locations 68, 8, and 5, and in Fig. 7 for locations 58 and 57) are owing to errors in the estimation of the radar-derived wave propagation direction during low-wave conditions. Values of $K_{r}>1$ also are owing to the increased water depths observed at stations 5 and 56. The effects of wave dissipation (green symbols in Figs. 6 and 7) are strong along the middle portion of both transects, and are particularly strong at 

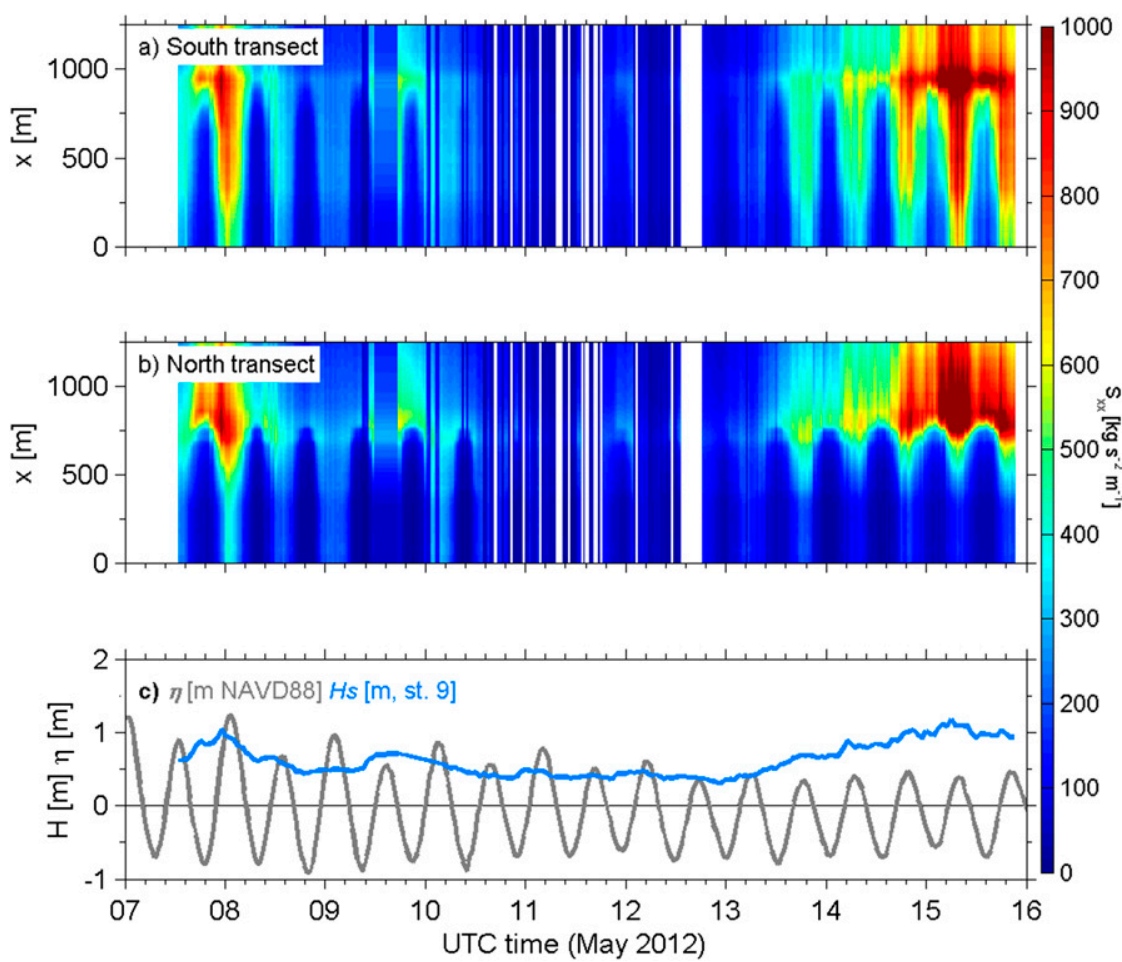

FIG. 9. Predicted cross-shore radiation stress (color contours, scale on the right) as a function of cross-shore location and time for the (a) north and (b) south channels. (c) Observed offshore significant wave height (blue curve) and tidal elevation (gray curve) vs time.

stations 8 and 7 (Fig. 6) and 57 and 56 (Fig. 7). Seaward of 8 and 57 , the water depth is such that depth-limited breaking rarely is observed, and $K_{D}$ is approximately equal to one. Landward of 6 and 56 , much of the wave energy has dissipated and $K_{D}$ again approaches one, except during the high-wave conditions of 7-10 and 1315 May (Figs. 6 and 7).

One possible cause of the differences between the radar-based predicted and the observed wave heights is the neglect of currents in the model [Eq. (4)]. The normalized residual wave height, computed as the sum of the predicted minus the measured divided by the measured $H_{\text {rms }}$, is negatively correlated with the water level, a proxy for tidal currents, at stations $5,6,7$, and $55(R=-0.79$, $-0.61,-0.42$, and -0.44 , respectively), and positively correlated with currents at stations 55 and $56(R=0.44$ and 0.35 , respectively). Correlation with tidal currents along the south transect is not statistically significant. Another possible cause of differences is error in the radar-derived bathymetry. The depth profiles along the south and north transects estimated with cBathy agree reasonably well with those interpolated from the bathymetric survey of 17 May (Fig. 8; $R=0.96$ and 0.95 for the south and north transects, respectively; bias $=-0.26$ and $-0.54 \mathrm{~m}$, respectively; RMSE $=0.61$ and $0.89 \mathrm{~m}$, respectively). Differences between weekly surveys from 27
April and 17 May were small. Although the cBathy and in situ estimates of water depth are similar, at some locations along the transects, the cBathy depths are more than $1 \mathrm{~m}$ deeper than the in situ depth estimates (Fig. 8). However, using the in situ-estimated bathymetry did not change the results significantly (Table 1).

A parametric model (Janssen and Battjes 2007) also was used to estimate wave heights, as originally formulated, with $B=1$ and $Q_{b}$ given by

$Q_{b}=1+\frac{4}{3 \sqrt{\pi}}\left(R^{3}+\frac{3}{2} R\right) \exp \left(-R^{2}\right)-\operatorname{erf}(R)$,

where $R=H_{b} / H_{\mathrm{rms}}, H_{b}=h\left[0.39+0.56 \tanh \left(33 S_{0}\right)\right]$, and $S_{0}=H_{\text {rms }}$ (deep water) $/ L_{0}$ (deep water), rather than using the radar-derived $Q_{b}$. The corresponding predicted wave heights had poorer agreement with the in situ observations along both the south $(R=0.24-0.95$, bias $=$ $0.02-0.29 \mathrm{~m}$, and RMSE $=0.06-0.35 \mathrm{~m})$ and north $(R=$ $0.41-0.96$, bias $=0.12-0.29 \mathrm{~m}$, and RMSE $=0.13$ $0.34 \mathrm{~m})$ transects than did the predictions using radarderived $Q_{b}$ (Table 1 ).

To assess the sensitivity of the wave transformation model to the breaking threshold, tests were run for $-8<$ $\sigma_{\mathrm{br}}^{0}<0 \mathrm{~dB}$, representing overestimation to underestimation of the breaking-induced dissipation. The agreement 

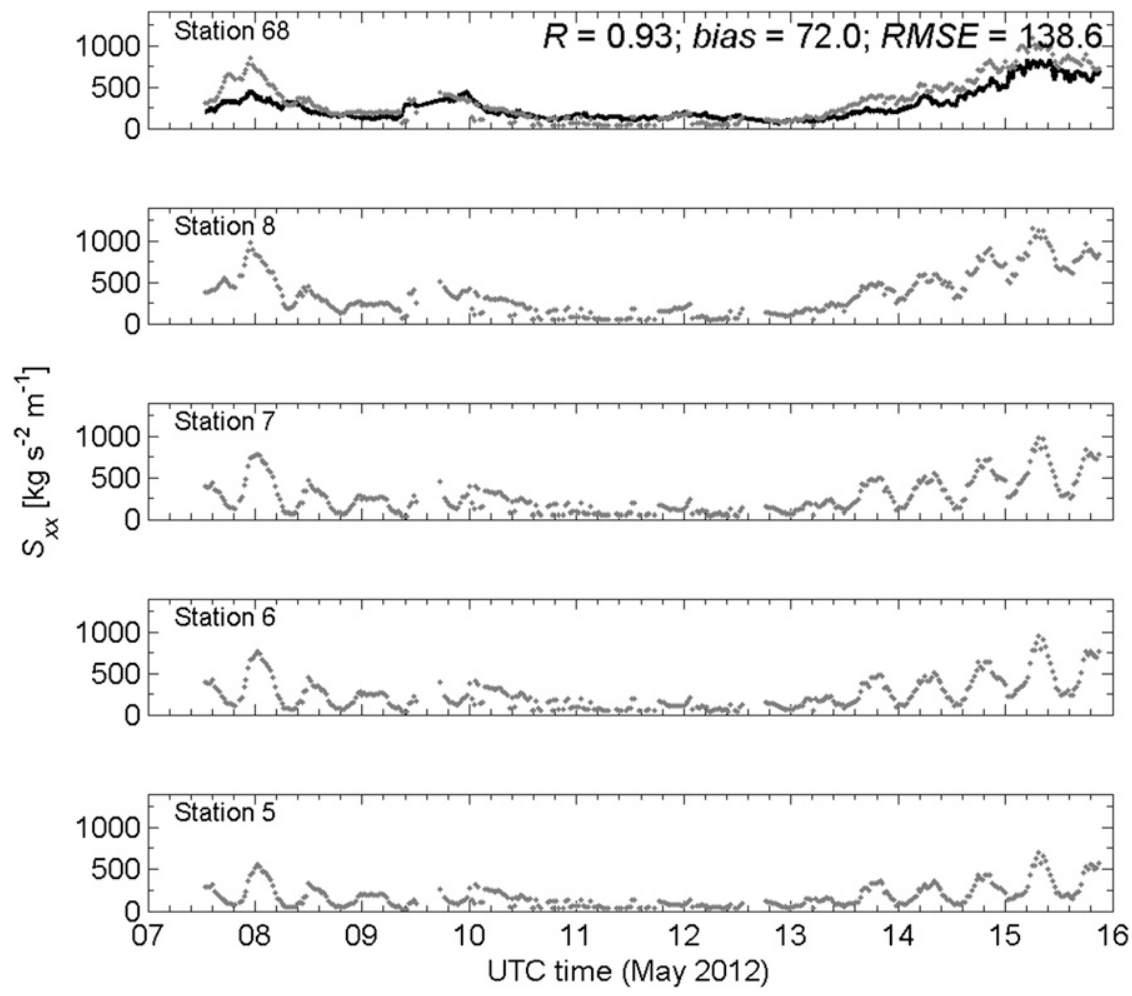

FIG. 10. Predicted (gray) and observed (black) cross-shore wave radiation stress $S_{x x}$ vs time for locations along the south inlet transect (sensors 5-8 and 68, Fig. 1).

between the predicted and the observed wave height at stations 58 and 68 did not vary with the different threshold values, because wave breaking seldom occurred there. The correlations between predicted and observed wave heights along both the south and north transects varied by less than $7 \%$ over the range of $\sigma_{\mathrm{br}}^{0}$ tested, and the RMSE and bias changed by less than $0.04 \mathrm{~m}$, suggesting that the breaking threshold within this range has a relatively small effect on the wave dissipation and therefore on model skill along each of the cross-shore transects.

The methodology for using radar observations to estimate wave transformation also allows spatially dense estimates of radiation stresses and their gradients along the transects (Fig. 9). The radar-derived estimates of radiation stress (south and north, Figs. 9a and 9b, respectively) are tidally modulated and increase as the wave height (Fig. 9c, blue curve) increases. Moreover, radar-derived estimates of radiation stress are similar to those estimated from in situ acoustic Doppler velocimeters (ADVs) at the offshore end of the south transect (Fig. 10, sensor 68, $R=0.93$ ) and along the north transect (Fig. 11, sensors 55-58, $0.79<R<0.95$ ), where a positive bias $\left(108-191 \mathrm{~kg} \mathrm{~s}^{-2} \mathrm{~m}^{-1}\right)$ is indicative of overprediction of radiation stress.

To assess the accuracy of the radar-derived wave forcing estimates, the along-transect gradient of the predicted cross-shore radiation stress (i.e., $\partial S_{x x} / \partial x$ ) was computed by locally calculating the energy flux with Eq. (4), and then using Eq. (6) to estimate the corresponding gradient as a two-point difference between the first and last grid points along the south transect, and between the grid points corresponding to stations 55 and 58 along the north transect. The latter was in good agreement $(R=$ 0.95 , bias $=0.15 \mathrm{~kg} \mathrm{~s}^{-2} \mathrm{~m}^{-1}$, RMSE $=0.23 \mathrm{~kg} \mathrm{~s}^{-2} \mathrm{~m}^{-1}$ ) with wave forcing from in situ measurements estimated in the same manner (Fig. 12b, black curve). These gradients computed using wave parameters derived from the spectral peak are consistent with those computed using the centroidal (energy weighted) frequency and direction (Wargula et al. 2014). In particular, both remotely sensed and in situ estimates have onshore (positive) forcing during the high-wave conditions (Fig. 12, 7-10 and 13-15 May), and would thus tend to enhance flood flows into the inlet (Wargula et al. 2014).

\section{Conclusions}

Radar-derived estimates of bathymetry, wave propagation direction, and the fraction of breaking waves combined with wave heights measured in 9-m water depth and a $1 \mathrm{D}$ wave transformation model that neglects the presence of currents, accurately predict the observed 

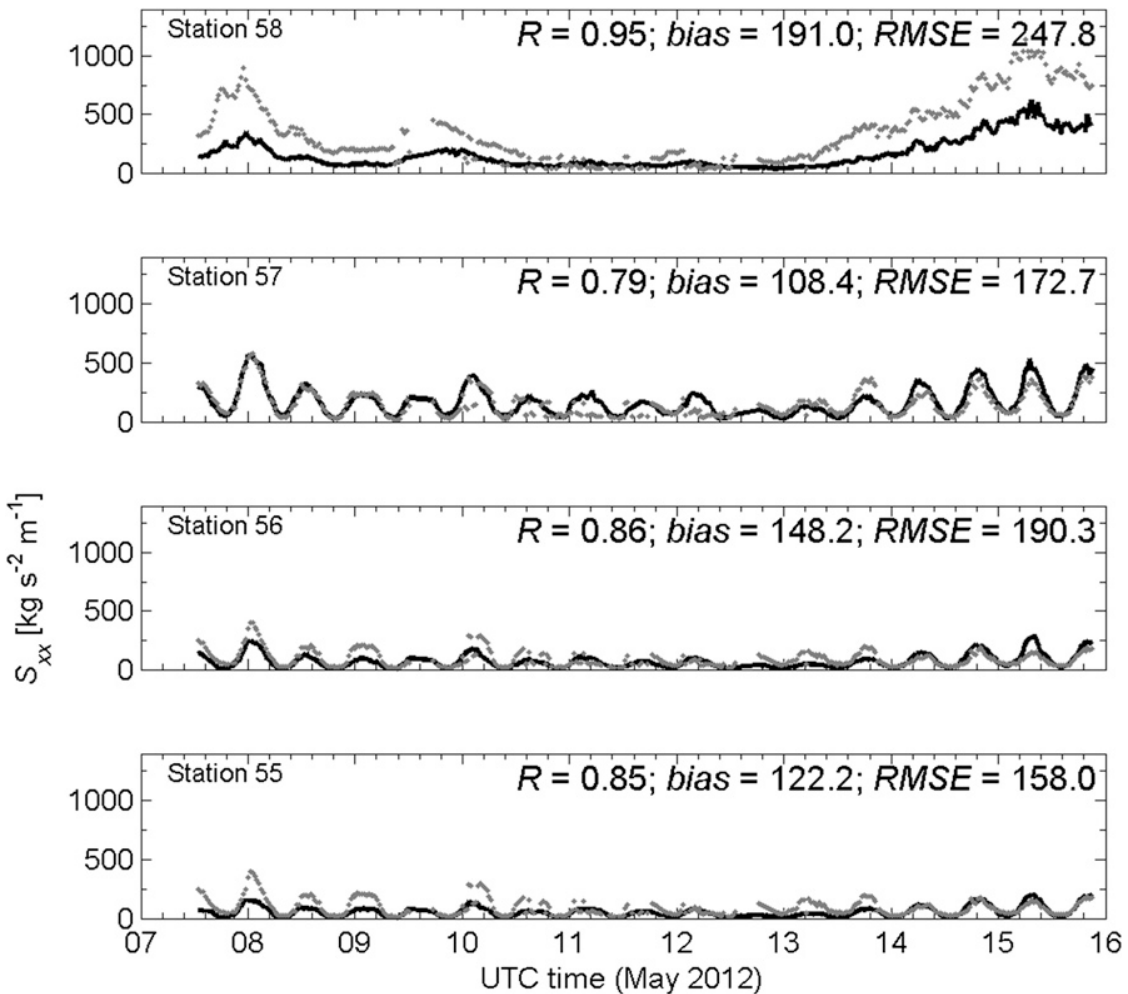

FIG. 11. Predicted (gray) and observed (black) cross-shore wave radiation stress $S_{x x}$ vs time for locations along the north inlet transect (sensors 55-58, Fig. 1).

evolution of wave heights and radiation stresses across a complex ebb shoal incised by two inlet channels. Wave heights across the ebb shoal (approximately 2-5-m depth) predicted using the radar-based methodology were modulated by tidal depth changes $( \pm 1 \mathrm{~m})$, consistent with observations and with previous numerical modeling results (Chen et al. 2014, manuscript submitted to J. Geophys. Res. Oceans). The modeled wave
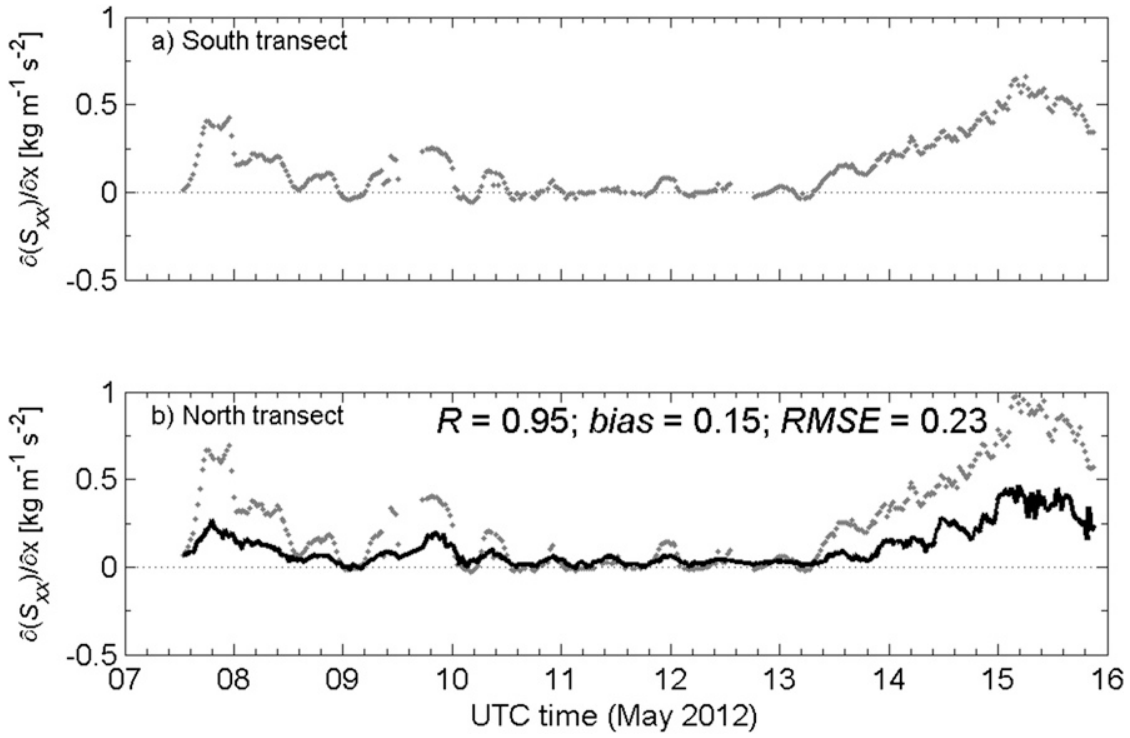

FIG. 12. Predicted (gray) and measured (black) wave forcing, computed as the along-inlet gradient of the cross-shore radiation stress $S_{x x}$, vs time for the (a) south and (b) north inlet transects. Predictions and observations used the frequency and direction of the waves at the peak of the frequency spectrum. 
heights incorporating the radar measurements agreed better with the observations than wave heights estimated using a parametric model with default settings. Using the radar images of the ocean surface allows spatially dense estimates of radiation stresses and their gradients. During energetic waves, radar-estimated radiation-stress gradients would force water into the inlet, similar to gradients estimated from in situ observations (Wargula et al. 2014).

Acknowledgments. These data were collected as part of a joint field program, Data Assimilation and Remote Sensing for Littoral Applications (DARLA) and Rivers and Inlets (RIVET-1), both funded by the Office of Naval Research. We gratefully acknowledge D. Trizna from ISR and R. Pittman from OSU for their assistance with radar deployment and data collection; R. Holman and J. Stanley from the Coastal Imaging Lab, OSU, for the ARGUS video data; J. Thomson from APL-UW for the wind data; J. McNinch and the USACE-FRF for the bathymetric data; G. Farquharson from APL-UW for installing the scaffolding structure; and the PVLAB field crew for deploying, maintaining, and recovering the in situ sensors in less-than-pleasant conditions. Many thanks to the reviewers of this paper for their comments and suggestions. The authors were funded through the Office of Naval Research Grant N00014-10-1-0932 and the Office of the Assistant Secretary of Defense for Research and Engineering.

\section{REFERENCES}

Bertin, X., A. Fortunato, and A. Oliveira, 2009: A modeling-based analysis of processes driving wave-dominated inlets. Cont. Shelf Res., 29, 819-834, doi:10.1016/j.csr.2008.12.019.

Catalán, P. A., M. C. Haller, R. A. Holman, and W. J. Plant, 2011: Optical and wave detection of wave breaking in the surf zone. IEEE Trans. Geosci. Remote Sens., 49, 1879-1893, doi:10.1109/ TGRS.2010.2095864.

,-- , and W. J. Plant, 2014: Microwave backscattering from surf zone waves. J. Geophys. Res. Oceans, 119, 3098-3120, doi:10.1002/2014JC009880.

Dodet, G., X. Bertin, N. Bruneau, A. B. Fortunato, A. Nahon, and A. Roland, 2013: Wave-current interactions in a wavedominated tidal inlet. J. Geophys. Res. Oceans, 118, 1587-1605, doi:10.1002/jgrc.20146.

Farquharson, G., S. J. Frasier, B. Raubenheimer, and S. Elgar, 2005: Microwave radar cross sections and Doppler velocities measured in the surf zone. J. Geophys. Res., 110, C12024, doi:10.1029/2005JC003022.

Flores, R. P., P. A. Catalán, and M. C. Haller, 2013: Incorporating remotely-sensed roller properties into set-up estimations for random wave conditions. Proc. Seventh Int. Conf. on Coastal Dynamics, Arcachon, France, CNRS, 615-626.

Gommenginger, C. P., N. P. Ward, G. J. Fisher, I. S. Robinson, and S. R. Boxall, 2000: Quantitative microwave backscatter measurements from the ocean surface using digital marine radar images. J. Atmos. Oceanic Technol., 17, 665-678, doi:10.1175/ 1520-0426(2000)017<0665:QMBMFT>2.0.CO;2.

Haller, M. C., and D. R. Lyzenga, 2003: Comparison of radar and video observations of shallow water breaking waves. IEEE Trans. Geosci. Remote Sens., 41, 832-844, doi:10.1109/TGRS.2003.810695.

_ _ and P. A. Catalán, 2009: Remote sensing of wave roller lengths in the laboratory. J. Geophys. Res., 114, C07022, doi:10.1029/ 2008JC005185.

Holman, R., and M. C. Haller, 2013: Remote sensing of the nearshore. Annu. Rev. Mar. Sci., 5, 95-113, doi:10.1146/ annurev-marine-121211-172408.

_, N. Plant, and T. Holland, 2013: cBathy: A robust algorithm for estimating nearshore bathymetry. J. Geophys. Res. Oceans, 118, 2595-2609, doi:10.1002/jgrc.20199.

Janssen, T. T., and J. A. Battjes, 2007: A note on wave energy dissipation over steep beaches. Coastal Eng., 54, 711-716, doi:10.1016/j.coastaleng.2007.05.006.

Kirby, J. T., 1984: A note on linear surface wave-current interaction over slowly varying topography. J. Geophys. Res., 89, 745-747, doi:10.1029/JC089iC01p00745.

Longuet-Higgins, M. S., and R. W. Stewart, 1964: Radiation stresses in water waves; A physical discussion, with applications. Deep-Sea Res. Oceanogr. Abstr., 11,529-562, doi:10.1016/ 0011-7471(64)90001-4.

Malhadas, M., P. Leitão, A. Silva, and R. Neves, 2009: Effect of coastal waves on sea level in Óbidos Lagoon, Portugal. Cont. Shelf Res., 29, 1240-1250, doi:10.1016/j.csr.2009.02.007.

McGregor, J. A., E. M. Poulter, and M. J. Smith, 1998: $S$ band Doppler radar measurements of bathymetry, wave energy fluxes, and dissipation across an offshore bar. J. Geophys. Res., 103, 18 779-18 789, doi:10.1029/98JC00447.

Orescanin, M., B. Raubenheimer, and S. Elgar, 2014: Observations of wave effects on inlet circulation. Cont. Shelf Res., 82, 37-42, doi:10.1016/j.csr.2014.04.010.

Svendsen, I. A., 2006: Introduction to Nearshore Hydrodynamics. Advanced Series on Ocean Engineering, Vol. 24, World Scientific, $722 \mathrm{pp}$.

Trizna, D., J. P. Hansen, P. Hwang, and J. Wu, 1991: Laboratory studies of sea spikes at low grazing angles. J. Geophys. Res., 96, 12 529-12 537, doi:10.1029/91JC00705.

Wargula, A., B. Raubenheimer, and S. Elgar, 2014: Wind-driven along-channel subtidal flows in a well-mixed ocean inlet. J. Geophys. Res. Oceans, 119,2987-3001, doi:10.1002/2014JC009839.

Willmott, C. J., 1981: On the validation of models. Phys. Geogr., 2, 184-194.

Young, I. R., W. Rosenthal, and F. Ziemer, 1985: A threedimensional analysis of marine radar images for the determination of ocean wave directionality and surface currents. J. Geophys. Res., 90, 1049-1059, doi:10.1029/JC090iC01p01049.

Zippel, S., and J. Thomson, 2015: Wave breaking and turbulence at a tidal inlet. J. Geophys. Res. Oceans, doi:10.1002/2014JC010025, in press. 